\title{
Orthogonal Experiments for Effect of Components on Performance Parameters of Green Sand for High Density Moulding
}

\author{
GAO Guili \\ College of Material Science and \\ Engineering \\ Harbin University of Science \& \\ Technology,Harbin, P. R. China \\ gao-guili@163.com
}

\author{
SHI Dequan \\ College of Material Science and \\ Engineering \\ Harbin University of Science \& \\ Technology,Harbin, P. R. China \\ shidequan2008@163.com
}

\author{
WANG Lihua \\ College of Material Science and \\ Engineering \\ Harbin University of Science \& \\ Technology,Harbin, P. R. China
}

\begin{abstract}
Under considering the interaction of the factors, the effects of the clay content, moisture content and coal content on the compactibility, permeability, green compressive strength and shatter index of green sand for high density moulding have been studied according to the orthogonal experimental method. The experimental results lead to the following conclusions. The optimal combination is that the clay content is $8 \%$, the moisture content is $3.2 \%$ and the coal content is $5 \%$. The moisture content is the strongest factor affecting the compactibility and permeability. The clay content is the most significant factor affecting the green compressive strength and shatter index. The interaction between the clay content and moisture content has key effect on the permeability, green compressive strength and shatter index, so the optimal ration of the clay content and the moisture content must be achieved. The effect of the coal content on the permeability, green compressive strength and shatter index is too less than that of the clay content and moisture content.
\end{abstract}

Keywords-Orthogonal experiment; component optimization; green sand; compactability; permeability

\section{INTRODUCTION}

The green sand casting has become the main method because of simple process, high productivity and low cost [1]. The high density moulding is widely used for online producing the castings of engine, and its advantages are much more clay and less moisture content, with purpose of controlling the expansion, shrinkage and rebound to the minimum or within a certain range [2]. The quality of green sand will directly affect the castings quality, especially for thin-walled porous parts. Statistics show that the rejected castings caused by the quality of green sand account for more than half of all wastes [3]. Therefore, to control the green sand quality has been one of the important topics in foundry. During the production, the property parameters of green sand are often used to predict if the casting defects will occur, but the property parameters depend on the components. Therefore, it is necessary to study the effect of components on the property parameters, and thus the optimal proportion for components is obtained.
Under taking account of the factor interactions, the effects of clay content, moisture content and coal content on the property parameters such as compactibility, permeability, green compressive strength and shatter index have been studied according to the orthogonal experimental method. And the optimal proportion has been got, which provides the basis for controlling the green sand production process.

\section{ORTHOGONAL EXPERIMENTAL DESIGN}

The green sand is composed of the quartz sand, clay, water coal and other additive. When the components are uniformly mixed, the uniform clay films surrounding the sand will form, and thus the green sand has the certain performances. Different component plays a different role in the green sand, and the component content directly determines the performance $[4,5]$. However, the components of green sand, especially clay, water and coal powder, are not in function separately, but in interaction between them. Therefore, this interaction can not be ignored when the effect of the major components on the performances is studied.

According to the actual production requirements, we take the clay content, moisture content and coal content as the factors, and give the levels of each factor, as shown in Table I. Based on the principle of orthogonal experimental design [6], the table $\mathrm{L}_{27}\left(3^{13}\right)$ is used for arranging the experiments with considering the interactions between the clay, moisture and coal. By the experiments, the effects of factors on the performances such as compactiblity, permeability, green compressive strength and shatter index are studied, and the experimental arrangement is shown in Table II.

TABLE I. THE FACTORS AND LEVELS OF GREEN SAND COMPONENTS

\begin{tabular}{|c|c|c|c|}
\hline \multirow{2}{*}{ levels } & \multicolumn{3}{|c|}{ factors } \\
\cline { 2 - 4 } & A: Clay (\%) & B: Moisture (\%) & C: Coal(\%) \\
\hline 1 & 4 & 1.5 & 1 \\
\hline 2 & 8 & 3.2 & 5 \\
\hline 3 & 12 & 5.0 & 9 \\
\hline
\end{tabular}


TABLE II. ORTHOGONAL EXPERIMENTAL DESIGN AND RESULT ANALYSIS

\begin{tabular}{|c|c|c|c|c|c|c|c|c|c|c|c|c|c|c|}
\hline \multirow{2}{*}{\multicolumn{2}{|c|}{ No }} & \multicolumn{9}{|c|}{ Column } & \multirow[b]{2}{*}{$\mathrm{I}^{\mathrm{a}}(\%)$} & \multirow[b]{2}{*}{$\mathrm{II}^{\mathrm{b}}$} & \multirow[b]{2}{*}{$\mathrm{III}^{\mathrm{c}}(\mathrm{kPa})$} & \multirow[b]{2}{*}{$\operatorname{IV}^{\mathrm{d}}(\%)$} \\
\hline & & $\begin{array}{l}1 \\
\mathrm{~A}\end{array}$ & $\begin{array}{l}2 \\
\text { B }\end{array}$ & $\begin{array}{c}3 \\
\mathrm{~A} \times \mathrm{B}\end{array}$ & $\begin{array}{c}4 \\
\mathrm{~A} \times \mathrm{B}\end{array}$ & $\begin{array}{l}5 \\
\mathrm{C}\end{array}$ & $\begin{array}{c}6 \\
\mathrm{~A} \times \mathrm{C}\end{array}$ & $\begin{array}{c}7 \\
\mathrm{~A} \times \mathrm{C}\end{array}$ & $\begin{array}{c}8 \\
\mathrm{~B} \times \mathrm{C}\end{array}$ & $\begin{array}{c}11 \\
\mathrm{~B} \times \mathrm{C}\end{array}$ & & & & \\
\hline \multicolumn{2}{|c|}{1} & 1 & 1 & 1 & 1 & 1 & 1 & 1 & 1 & 1 & 30.1 & 100 & 115 & 59 \\
\hline \multicolumn{2}{|c|}{2} & 1 & 1 & 1 & 1 & 2 & 2 & 2 & 2 & 2 & 27.9 & 102 & 121 & 56 \\
\hline \multicolumn{2}{|c|}{3} & 1 & 1 & 1 & 1 & 3 & 3 & 3 & 3 & 3 & 25.2 & 107 & 117 & 55 \\
\hline \multicolumn{2}{|c|}{4} & 1 & 2 & 2 & 2 & 1 & 1 & 1 & 2 & 3 & 40.3 & 115 & 121 & 67 \\
\hline \multicolumn{2}{|c|}{5} & 1 & 2 & 2 & 2 & 2 & 2 & 2 & 3 & 1 & 38.1 & 117 & 130 & 70 \\
\hline \multicolumn{2}{|c|}{6} & 1 & 2 & 2 & 2 & 3 & 3 & 3 & 1 & 2 & 38.8 & 112 & 127 & 61 \\
\hline \multicolumn{2}{|c|}{7} & 1 & 3 & 3 & 3 & 1 & 1 & 1 & 3 & 2 & 38.5 & 111 & 102 & 65 \\
\hline \multicolumn{2}{|c|}{8} & 1 & 3 & 3 & 3 & 2 & 2 & 2 & 1 & 3 & 40.4 & 115 & 103 & 64 \\
\hline \multicolumn{2}{|c|}{9} & 1 & 3 & 3 & 3 & 3 & 3 & 3 & 2 & 1 & 37.2 & 110 & 112 & 59 \\
\hline \multicolumn{2}{|c|}{10} & 2 & 1 & 2 & 3 & 1 & 2 & 3 & 1 & 1 & 38.9 & 92 & 122 & 62 \\
\hline \multicolumn{2}{|c|}{11} & 2 & 1 & 2 & 3 & 2 & 3 & 1 & 2 & 2 & 36.6 & 98 & 129 & 68 \\
\hline \multicolumn{2}{|c|}{12} & 2 & 1 & 2 & 3 & 3 & 1 & 2 & 3 & 3 & 32.3 & 102 & 132 & 67 \\
\hline \multicolumn{2}{|c|}{13} & 2 & 2 & 3 & 1 & 1 & 2 & 3 & 2 & 3 & 46.2 & 126 & 146 & 81 \\
\hline & & 2 & 2 & 3 & 1 & 2 & 3 & 1 & 3 & 1 & 47.1 & 142 & 158 & 79 \\
\hline & & 2 & 2 & 3 & 1 & 3 & 1 & 2 & 1 & 2 & 45.6 & 131 & 151 & 78 \\
\hline & & 2 & 3 & 1 & 2 & 1 & 2 & 3 & 3 & 2 & 43.2 & 118 & 140 & 67 \\
\hline & & 2 & 3 & 1 & 2 & 2 & 3 & 1 & 1 & 3 & 40.7 & 130 & 131 & 69 \\
\hline & & 2 & 3 & 1 & 2 & 3 & 1 & 2 & 2 & 1 & 37.1 & 131 & 136 & 68 \\
\hline & & 3 & 1 & 3 & 2 & 1 & 3 & 2 & 1 & 1 & 32.3 & 97 & 90 & 50 \\
\hline & & 3 & 1 & 3 & 2 & 2 & 1 & 3 & 2 & 2 & 29.4 & 105 & 96 & 46 \\
\hline & & 3 & 1 & 3 & 2 & 3 & 2 & 1 & 3 & 3 & 26.1 & 113 & 104 & 48 \\
\hline & & 3 & 2 & 1 & 3 & 1 & 3 & 2 & 2 & 3 & 38.6 & 121 & 115 & 58 \\
\hline & & 3 & 2 & 1 & 3 & 2 & 1 & 3 & 3 & 1 & 42.5 & 119 & 121 & 61 \\
\hline & & 3 & 2 & 1 & 3 & 3 & 2 & 1 & 1 & 2 & 39.1 & 123 & 118 & 54 \\
\hline & & 3 & 3 & 2 & 1 & 1 & 3 & 2 & 3 & 2 & 44.1 & 126 & 132 & 70 \\
\hline & & 3 & 3 & 2 & 1 & 2 & 1 & 3 & 1 & 3 & 42.2 & 130 & 138 & 65 \\
\hline & & 3 & 3 & 2 & 1 & 3 & 2 & 1 & 2 & 1 & 40.8 & 127 & 146 & 60 \\
\hline & $\mathrm{k}_{1}$ & 35.2 & 31.0 & 36.0 & 38.8 & 39.1 & 37.6 & 37.7 & 38.7 & 38.2 & & & & \\
\hline $\mathrm{I}^{\mathrm{a}}$ & $\mathrm{k}_{2}$ & 40.9 & 41.8 & 39.1 & 36.2 & 38.3 & 37.9 & 37.4 & 37.1 & 38.1 & & & & \\
\hline & $\mathrm{k}_{3}$ & 37.2 & 40.5 & 38.1 & 38.2 & 35.8 & 37.8 & 37.5 & 37.5 & 36.9 & & & & \\
\hline & $\mathrm{R}_{1}$ & 5.7 & 10.8 & 3.1 & 2.6 & 3.3 & 0.3 & 0.1 & 1.6 & 1.3 & & $\rightarrow \mathrm{C} \rightarrow$ & $\mathrm{B} \rightarrow \mathrm{B} \times \mathrm{C} \rightarrow$ & $\times \mathrm{C}$ \\
\hline & $\mathrm{k}_{1}$ & 109.9 & 101.8 & 116.8 & 121.2 & 111.8 & 116.0 & 117.7 & 114.4 & 115.0 & & & & \\
\hline $\mathrm{UI}^{\mathrm{b}}$ & $\mathrm{k}_{2}$ & 118.9 & 122.9 & 113.2 & 115.3 & 117.6 & 114.8 & 115.8 & 115.0 & 114.0 & & & & \\
\hline & $\mathrm{k}_{3}$ & 117.9 & 122.0 & 116.7 & 110.1 & 117.3 & 115.9 & 112.7 & 117.2 & 117.7 & & & & \\
\hline & $\mathrm{R}_{2}$ & 9.0 & 21.1 & 3.6 & 11.1 & 5.8 & 1.2 & 5.0 & 2.8 & 3.7 & & $\mathrm{~B} \rightarrow \mathrm{A}$ & $\mathrm{C} \rightarrow \mathrm{A} \times \mathrm{C}-$ & $\times \mathrm{C}$ \\
\hline & $\mathrm{k}_{1}$ & 116.4 & 114.0 & 123.8 & 136.0 & 120.3 & 123.6 & 124.9 & 121.7 & 125.6 & & & & \\
\hline $\mathrm{HIJ}^{\mathrm{c}}$ & $\mathrm{k}_{2}$ & 138.3 & 131.9 & 130.8 & 119.4 & 125.2 & 125.6 & 123.3 & 124.7 & 124.0 & & & & \\
\hline & $\mathrm{k}_{3}$ & 117.8 & 126.7 & 118.0 & 117.1 & 127.0 & 123.4 & 124.8 & 126.2 & 123.0 & & & & \\
\hline & $\mathrm{R}_{3}$ & 21.9 & 17.9 & 12.8 & 18.9 & 6.7 & 2.1 & 1.6 & 4.6 & 2.6 & & $\mathrm{~B} \rightarrow \mathrm{B}$ & $\mathrm{C} \rightarrow \mathrm{B} \times \mathrm{C} \rightarrow$ & $\times \mathrm{C}$ \\
\hline & $\mathrm{k}_{1}$ & 61.8 & 56.8 & 60.8 & 67.0 & 64.3 & 64.0 & 63.2 & 62.4 & 63.1 & & & & \\
\hline $\mathrm{IV}^{\mathrm{d}}$ & $\mathrm{k}_{2}$ & 71.0 & 67.7 & 65.6 & 60.7 & 64.2 & 62.4 & 64.6 & 62.6 & 62.8 & & & & \\
\hline & $\mathrm{k}_{3}$ & 56.9 & 65.2 & 63.3 & 62.0 & 61.1 & 63.2 & 62.0 & 64.7 & 63.8 & & & & \\
\hline & $\mathrm{R}_{4}$ & 14.1 & 10.9 & 4.8 & 6.3 & 3.2 & 1.6 & 2.6 & 2.2 & 1.0 & & $\rightarrow \mathrm{A} \times \mathrm{B}$ & $\mathrm{C} \rightarrow \mathrm{A} \times \mathrm{C}-$ & $\times \mathrm{C}$ \\
\hline
\end{tabular}

\section{RESUltS AND ANALYSIS}

The experimental results are shown in Table II. The average values $k_{i}$ and the ranges $R_{i}$ of compactibility, permeability, green compressive strength and shatter index calculated respectively according to the different factor and level. Therefore, the sequence of the factors affecting every performance of green sand can be given according to the value of the ranges $R_{i}$. It can be seen from the ranges $R_{i}$ that the interactions between the clay content, moisture content and coal content do exist. So, when the optimal levels of the factors are chosen, the interactions must be further analyzed. The following is the further analysis for each performance parameter. 


\section{A. Compactability}

We can conclude from Table II that the sequence of the factors affecting compactiblity is $\mathrm{B} \rightarrow \mathrm{A} \rightarrow \mathrm{C} \rightarrow \mathrm{A} \times \mathrm{B} \rightarrow \mathrm{B} \times \mathrm{C}$, namely, moisture content $\rightarrow$ clay content $\rightarrow$ coal content $\rightarrow$ interaction between clay and moisture $\rightarrow$ interaction between moisture and coal. The effect of the interaction between clay and moisture is same as that of the coal content. But the interaction between clay and coal is found to have little effect on the compactiblity, and so it can be neglected. The data of the interactions of $\mathrm{A} \times \mathrm{B}$ and $\mathrm{B} \times \mathrm{C}$ can be got from the Table II, which is shown in Table III. And the interaction diagram can be plotted as Fig.1.

TABLE III. THE COMPACTABILITY DATA FOR FACTOR INTERACTIONS

\begin{tabular}{|c|c|c|c||c|c|c|c|}
\hline B A & A1 & A2 & A3 & C B & B1 & B2 & B3 \\
\hline B1 & 27.7 & 36 & 29.3 & C1 & 33.8 & 39.7 & 41.9 \\
\hline B2 & 38.1 & 45.3 & 40.1 & C2 & 31.3 & 42.6 & 41.1 \\
\hline B3 & 38.7 & 43.8 & 42.4 & C3 & 27.9 & 39.2 & 38.4 \\
\hline
\end{tabular}
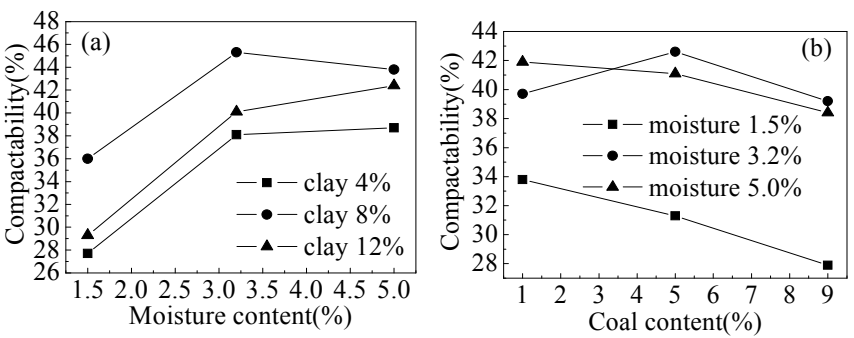

Figure 1 The interaction diagram for compactibility between the factor: (a)clay and moisture; (b)moisture and coal

As can be seen from Fig.1, the interactions between the factors do exist. Fig.1(a) shows that when the clay content is $8 \%$ and water content is $3.2 \%$, the compactiblity reaches the maximum of $46.3 \%$. Fig. 1 (b) shows that the compactibilty has a maximum value when the water content is $3.2 \%$ and the coal content is $5 \%$. Thus, the optimal levels for the compactibility are $8 \%$ clay, $3.2 \%$ moisture and $5 \%$ coal.

\section{B. Permeability}

The calculated results for permeability in Table II show that sequence of the factors affecting the permeability is $\mathrm{B} \rightarrow \mathrm{A} \times \mathrm{B} \rightarrow \mathrm{A} \rightarrow \mathrm{C} \rightarrow \mathrm{A} \times \mathrm{C} \rightarrow \mathrm{B} \times \mathrm{C}$, that is, moisture $\rightarrow$ interaction between clay and moisture $\rightarrow$ clay $\rightarrow$ coal $\rightarrow$ interaction between clay and coal $\rightarrow$ interaction between moisture and coal. The data in Table IV are used for analyzing the interaction of $\mathrm{A} \times \mathrm{B}, \mathrm{B} \times \mathrm{C}$ and $\mathrm{C} \times \mathrm{A}$. The interaction diagram for the permeability is shown in Fig.2.

TABLE IV. THE PERMEABILITY DATA FOR FACTOR INTERACTIONS

\begin{tabular}{|c|c|c|c||c|c|c|c||c|c|c|c|}
\hline B & A1 & A2 & A3 & C A & A1 & A2 & A3 & B C & C1 & C2 & C3 \\
\hline B1 & 103 & 97 & 105 & C1 & 109 & 112 & 115 & B1 & 96 & 102 & 107 \\
\hline B2 & 115 & 133 & 121 & C2 & 111 & 123 & 118 & B2 & 121 & 126 & 122 \\
\hline B3 & 112 & 126 & 128 & C3 & 110 & 121 & 120 & B3 & 118 & 125 & 123 \\
\hline
\end{tabular}

It can be drawn from Fig. 2 that the optimal combination of the levels is $\mathrm{A} 2 \mathrm{~B} 2 \mathrm{C} 2$, namely, the clay content is $8 \%$, the moisture content is $3.2 \%$ and the coal content is $5 \%$. As shown in Fig.2(a), when the clay content is $4 \%$ and $8 \%$, the permeability will go up and then down with the increase of moisture content. But when the clay content is $12 \%$, the permeability keeps going up with the increase of moisture content, however, the bigger the moisture content is, the smaller the increase degree of the permeability becomes. This indicates there is a suitable ratio between clay content and moisture content, and when this ratio is reached, the permeability of the green sand is highest. Fig.2(c) shows that the permeability is also satisfactory when the coal content is $9 \%$, which agreed with the fact that about $9 \%$ coal is sometimes used in foundry while the water content should also be improved. In addition, Fig. 2 also testifies that the interaction between the coal and the moisture is significantly lower than the interaction between the clay and the moisture or between the clay and the coal.
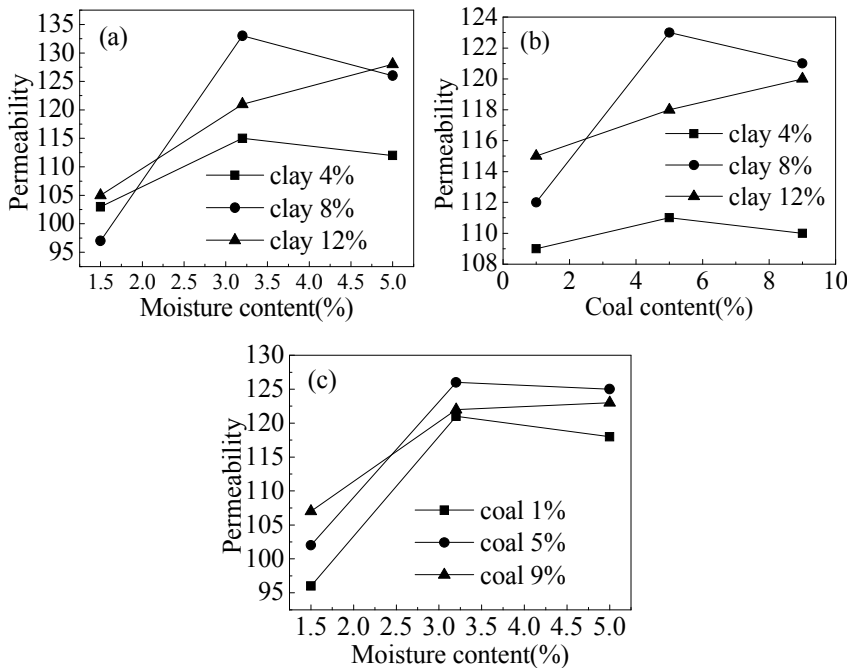

Figure 2 The interaction diagram for permeability between the factor: (a)clay and moisture; (b)clay and coal; (c)moisture and coal.

\section{Green Compressive Strength}

It can be concluded from Table II that the sequence of the factors affecting the green compressive strength can be written as $\mathrm{A} \rightarrow \mathrm{A} \times \mathrm{B} \rightarrow \mathrm{B} \rightarrow \mathrm{C} \rightarrow \mathrm{B} \times \mathrm{C} \rightarrow \mathrm{A} \times \mathrm{C}$, namely, the clay $\rightarrow$ interaction between the clay and moisture $\rightarrow$ moisture $\rightarrow$ coal $\rightarrow$ interaction between moisture and coal $\rightarrow$ interaction between clay and coal. Therefore, to ensure that the green sand have enough green compressive strength, much attention must be paid to the interaction between the clay content and the moisture content, and the suitable ratio between them must be reached. In addition, the clay content should be as higher as possible under the condition of controlling the moisture content. Because the range $R=2.1$ of the interaction between clay and coal is far less than the range $R=18.9$ of the interaction between clay and moisture, the former almost has not effect on the green compressive strength of green sand. Therefore, the data of the interaction of $\mathrm{A} \times \mathrm{B}$ and $\mathrm{B} \times \mathrm{C}$ interaction are shown in Table $\mathrm{V}$, and the interaction curve is plotted in Fig.3.

Fig. 3 shows that the reasonable ratio of having good green compressive strength is that the clay content is $8 \%$, the water content is $3.2 \%$ and the coal content is $5 \%$. In addition, Fig. 3 
also shows that green compressive strength of green sand reaches a certain value and then declines with the increase of the clay content or the moisture content, and only when the ratio of the clay content and the moisture content is reasonable, the strength can reach the maximum.

TABLE V. COMPRESSIVE STRENGTH DATA FOR FACTOR INTERACTIONS

\begin{tabular}{|c|c|c|c||c|c|c|c|}
\hline A B & B1 & B2 & B3 & B & C1 & C2 & C3 \\
\hline A1 & 118 & 126 & 106 & B1 & 109 & 115 & 118 \\
\hline A2 & 128 & 152 & 136 & B2 & 127 & 136 & 132 \\
\hline A3 & 97 & 118 & 139 & B3 & 125 & 124 & 131 \\
\hline
\end{tabular}
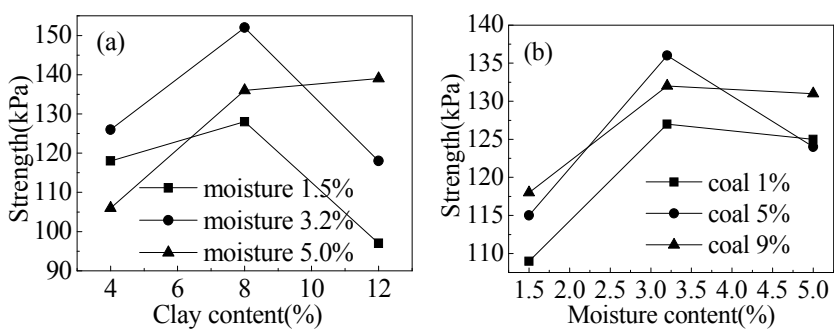

Figure 3 The interaction diagram for green compressive strength between the factor: (a)clay and moisture; (b)moisture and coal.

\section{Shatter Index}

Table II shows that the sequence of the factors affecting the shatter index is $\mathrm{A} \rightarrow \mathrm{B} \rightarrow \mathrm{A} \times \mathrm{B} \rightarrow \mathrm{C} \rightarrow \mathrm{A} \times \mathrm{C} \rightarrow \mathrm{B} \times \mathrm{C}$, that is, the clay $\rightarrow$ moisture $\rightarrow$ interaction between clay and moisture $\rightarrow$ coal $\rightarrow$ interaction between clay and coal $\rightarrow$ interaction between moisture and coal. The data of the interaction of $\mathrm{A} \times \mathrm{B}$, $\mathrm{B} \times \mathrm{C}$ and $\mathrm{C} \times \mathrm{A}$ are shown in Table VI, and the corresponding interaction diagram is shown in Fig.4.

TABLE VI. THE SHATTER INDEX DATA FOR FACTOR INTERACTIONS

\begin{tabular}{|c|c|c|c||c|c|c|c||c|c|c|c|}
\hline A $^{\text {B }}$ & B1 & B2 & B3 & B & C1 & C2 & C3 & A & C1 & C2 & C3 \\
\hline A1 & 57 & 66 & 63 & B1 & 57 & 57 & 56 & A1 & 64 & 63 & 58 \\
\hline A2 & 66 & 79 & 68 & B2 & 69 & 70 & 64 & A2 & 70 & 72 & 71 \\
\hline A3 & 48 & 58 & 65 & B3 & 67 & 66 & 62 & A3 & 59 & 57 & 54 \\
\hline
\end{tabular}
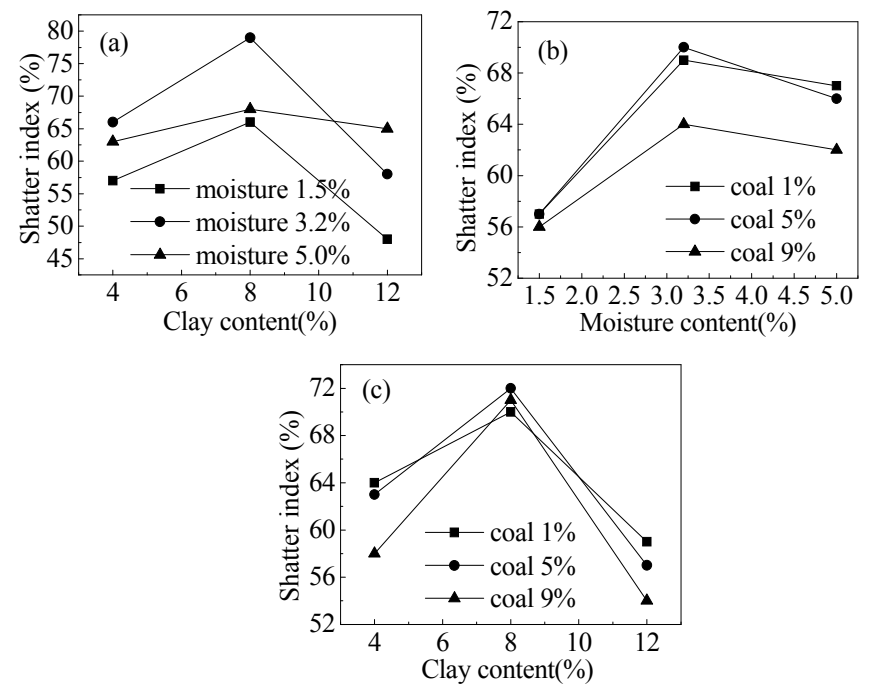

Figure 4 The interaction diagram for shatter index between the factor: (a)clay and moisture; (b)moisture and coal; (c)clay and coal.
As can be seen from Fig.4, the optimal combination of the levels for the shatter index is $\mathrm{A} 2 \mathrm{~B} 2 \mathrm{C} 2$, namely, the clay content is $8 \%$, the water content is $3.2 \%$ and the coal content is $5 \%$. The shatter index obtained in the experiments is $79 \%$ under this combination, which meets the practical requirement for the shatter index of $70 \%-80 \%$.

To sum up, the water content is the strongest factor that affects the compactibility and permeability of green sand. The clay content is the most important factor that affects the green compressive strength and shatter index. The interaction between the clay content and the moisture content has very important effect on the permeability and green compressive strength. So the optimal ration of the clay content and the moisture content must be reached in order to make the green sand have enough permeability and green compressive strength. In addition, the coal content also affects the permeability, green compressive strength and shatter index while its effect is less than that of interaction between the clay content and moisture content. However, the coal content can not be ignored in that it will directly determine the gas evolution of green sand. Therefore, comprehensively considering these four performance parameters, the optimal combination of green sand components is that the clay content is $8 \%$, the water content is $3.2 \%$ and the coal content is $5 \%$. Certainly, they can fluctuate depending on the production conditions.

\section{CONCLUSIONS}

The moisture content is the most key factor affecting compactibility and permeability of green sand. The most important factor affecting the green compressive strength and shatter index is the clay content. The interaction between the clay content and moisture content is the significant factor that affects the permeability, green compressive strength and shatter index. The effect degree of the coal content on the permeability, green compressive strength and shatter index is much lower than the effects of the clay content and moisture content. Under comprehensive consideration of performance parameters, the optimal combination for the high-density moulding is the $8 \%$ clay, $3.2 \%$ moisture and $5 \%$ coal.

\section{REFERENCES}

[1] S. G. Baker, "Building the foundation for green sand," Modern Casting, vol. 95, pp. 26-29, August 2005.

[2] R. L. Beaman, "The sand controversy: Does core sand harm your green sand?" Modern casting, vol. 94, pp. 34-37, May 2004.

[3] J. M. Beaman, J. F. Cuttino, and E. P. Morse, "Parameter influence on dimensional variation in green sand iron castings," AFS Transactions, vol. 115, pp. 349-366, February 2007.

[4] H. R. Xiao, and W. W. Zhang, "Intelligent moisture controlling system for molding sand," Advanced Materials Research, vol. 97-101, pp. 43094312, March 2010.

[5] S. Guharaja, A. Noorul Haq, and K. M. Karuppannan, "Optimization of green sand casting process parameters by using Taguchi's method," International Journal of Advanced Manufacturing Technology, vo. 30, pp. 1040-1048, October 2006.

[6] Q. S. He, X. N. Liu, and S. F. Xiao, "Application of orthogonal experimental design on reliability and sensitivity analysis," Advanced Materials Research, vol. 211-212, pp. 651-655, February 2011. 